\title{
AUTHOR(S): WARRENDER, D.
}

TITLE:

Borderline personality disorder and the ethics of risk management: the action/consequences model.

YEAR: $\quad 2018$

Publisher citation: WARRENDER, D. 2018. Borderline personality disorder and the ethics of risk management: the action/consequences model. Nursing ethics [online], 25(7), pages 918-927. Available from: https://doi.org/10.1177/0969733016679467

OpenAIR citation: WARRENDER, D. 2018. Borderline personality disorder and the ethics of risk management: the action/consequences model. Nursing ethics, 25(7), pages 918-927. Held on OpenAIR [online]. Available from: https://openair.rgu.ac.uk

\section{Publisher copyright statement:}

This is the AUTHOR ACCEPTED version of an article originally published by in Nursing ethics

(ISSN 0969-7330; eISSN 1477-0989).

\section{OpenAIR takedown statement:}

Section 6 of the "Repository policy for OpenAIR @ RGU" (available from http://www.rgu.ac.uk/staff-and-currentstudents/library/library-policies/repository-policies) provides guidance on the criteria under which RGU will consider withdrawing material from OpenAIR. If you believe that this item is subject to any of these criteria, or for any other reason should not be held on OpenAIR, then please contact openair-help@rgu.ac.uk with the details of the item and the nature of your complaint.

This publication is distributed under a CC BY-NC-ND 4.0 license. 


\title{
Borderline personality disorder and the ethics of risk management: The action/ consequences model
}

\begin{abstract}
Patients with borderline personality disorder are frequent users of inpatient mental health units, with inpatient crisis intervention often used based on the risk of suicide. However this can present an ethical dilemma for nursing and medical staff, with these clinician responses shifting between the moral principles of beneficence and non-maleficence, dependent on the outcomes of the actions of containing or tolerating risk. This paper examines the use of crisis intervention through moral duties, intentions and consequences, culminating in an action/consequences model of risk management, used to explore potential outcomes. This model may be useful in measuring adherence and violation of the principles of beneficence and non-maleficence, and therefore an aid to clinical decision making.
\end{abstract}

\section{Keywords}


Borderline personality disorder, ethics, risk management, beneficence, non-maleficence

\section{I ntroduction}

People with a diagnosis of borderline personality disorder (BPD) [1], also known as emotionally unstable personality disorder [2], are frequent users of mental health inpatient services [3]. These admissions can be both frequent and lengthy [4] and as such present many on-going challenges for clinicians from both nursing and medical professions. The characteristics of BPD are detailed by NICE [3] as instability in interpersonal relationships, impulsive behaviour, fear of abandonment and rejection, unstable self-image and a tendency towards self-harm and suicidal thinking. It is the potential for suicide completion which, understandably, acts as the primary reason for the intervention of mental health professionals. Some studies have estimated a suicide completion rate of up to $10 \%$ in people with BPD [5], a heavy contribution to the anxieties provoked in clinicians involved in the assessment and management of risk. However, the purpose and consequences of intervention are often 
neglected in the arena of ethics. This paper will look at the specific crisis intervention of acute mental health inpatient admission through discussion, and examine the core moral concepts of beneficence; to do good, and non-maleficence; to do no harm. These are concepts which can sometimes be at odds in crisis management, with the tension in clinical judgement creating an ethical fray between the poles of containing and tolerating risk. Moreover, there will also be an examination of the moral motivations behind risk specific measures, as duty to patients is weighed against clinician selfpreservation in the arena of accountability, public scrutiny and professional regulation. Morality can be viewed as a triage of rules, motives and consequences, and all will be related to specific responses to patients with a diagnosis of BPD who may present to mental health services when in crisis. This paper will conclude with the collation of issues into action/consequence model of BPD risk management, capturing the potential consequences of risk specific actions through a worked hypothetical example based on clinical experience. 
A crisis intervention is defined by Borshmann et al [6] as "an immediate response by one or more individuals to the acute distress experienced by another individual, which is designed to ensure safety and recovery and last no longer than one month". A common intervention to the acute distress of suicidal ideation is a crisis admission to an acute mental health ward, with an estimated $20 \%$ of mental health inpatients having a diagnosis of BPD [7]. These inpatient units are generally utilised with the aim of ensuring safety through containing risk. Nursing staff are available for support and reassurance; however the purpose of admission is often to use the inpatient unit as a safe haven, and a base from which staff can provide risk specific measures such as constant observations. Constant observation prescribes one to one nursing for patients deemed to pose a significant risk to themselves or others [8] and, for people diagnosed with BPD, is primarily used as a safeguard against an imminent risk of serious self-harm or suicide.

\section{Containing Risk}


At first glance, any situation whereby a patient expresses thoughts and intent of suicide completion clearly warrants an intervention of this nature. After all, nursing is the business of person-centred care and effective treatments, with safety prioritised through a policy of "no avoidable injury or harm" [9]. Beneficence would dictate nurses using all of their powers to maintain patient safety, with admission itself, and the on-going use of constant observations meeting these criteria. A further intervention could be the use of nurses holding power, and any use of the Mental Health Care and Treatment (Scotland) Act 2015 [10]. The beneficence, the very obvious good, of these containing interventions is in a Kantian [11] and deontological duty of care to patient safety.

\section{The Maleficence of Containment}

Nevertheless the ethical subtleties of such situations, in the context of working with people diagnosed with BPD, require a deeper scrutiny. Interventions may be both practical, and appear morally appropriate, yet still suffer unintended and sometimes negative consequences. The Scottish Government [8] acknowledges that 
“containment felt by some patients under observation may lead to deterioration in their behaviour". Observation is undoubtedly an invasive process, where staff nurses may observe patients sleeping, eating, interacting with family members and in some cases using the bathroom. Whilst this is all prescribed according to the level of perceived risk, it can understandably be frustrating to have personal space invaded, regardless of a clinician's virtuous intentions, or sense of duty.

Alternatively, yet still on an iatrogenic path, the level of patient frustration could shift to a detrimental level of reassurance experienced. NICE [3] states, on crisis interventions, that "the assessing clinician should consider that such a response might inadvertently increase the risk in the longer term by decreasing the patient's capacity to manage their own risk". Exploring the principle of non-maleficence, admission and constant observations can violate this, unintentionally disabling the patient by reinforcing their belief that they cannot keep themselves safe. In this way, health services can directly mirror the patients' anxiety, and respond with panic over 
any perceived risk of harm. Furthermore, maleficent consequences swell if containment is over a prolonged timescale, with long admissions increasing the patient's dependency. Any benefits of containment could be said to be tenuous, with the potential for such iatrogenic harm.

Coercive bondage is a term used by Hendin [12] which describes the transfer of the patients responsibility for their own personal safety to the clinician. In measures such as inpatient admission and constant observation, this transfer is acutely experienced by both parties. Having this process formalised through risk specific interventions emphasises the patient's helplessness and the clinician's role as 'saviour'. A challenge then comes, post crisis, in returning personal responsibility and autonomy to the patient. This is a factor which has the potential to influence lengthy admissions.

Moreover, the sense of security provided by nursing staff can reassure the patient through crisis, until the moment where intervention ends, and discharge is mentioned. The patient can then 
experience fresh crisis at the prospect of a perceived abandonment. This can see a counterproductive cycle of crisis which negates any beneficent intentioned and fruitful purpose for hospitalization. The patient can misunderstand the motives of clinicians, perhaps viewing discharge as an uncaring gesture, and can paradoxically become worse in hospital. Furthermore, due to this fear of perceived abandonment in many patients with BPD, the longer an admission goes on, the stronger the association becomes between the apprehension around discharge and the acute distress experienced.

At this point the clarity of the virtues, duty and intended beneficence of the initial risk management strategy is clouded by ethical ramifications which would haunt consequentialist thinking. Although the aim may have been to help the patient, the consequences can be the reverse. The patient may be 'safe', though they would not be considered 'well'.

\section{Tolerating Risk}


Containing risk seems, certainly initially, to be the only course of action for managing suicidal ideation in patients with BPD which ties in with the deep caring philosophy of nursing. Therefore it can be difficult for the layman to grasp why clinicians would ever tolerate any element of risk, particularly when it comes to the intimidating task of assessing the risk of suicide. However, whereas containing risk is no doubt beneficent in terms of its virtue and duty based motivation to maintain safety, interventions of this nature can lead, regardless of intention, to the consequential maleficence discussed. As we develop our understanding of BPD, we so too develop an awareness of the harm that crisis intervention can bring, and can now begin to consider a 'less is more' approach.

First and foremost given the potential for iatrogenic harm, tolerating risk can have beneficent outcomes, specifically the least restrictive care and the avoidance of unnecessary containment. Surprisingly given its frequent utilization, Paris [13] and Oldham [14] cite the alarming lack of evidence for hospital admission as a successful intervention in suicide prevention. Moreover there are claims, 
beyond this paper's ethical debate, that admission itself is neutral at best [15] potentially detrimental $[13,15,16]$, with particular concerns over the iatrogenic harm of long admissions [17]. Alarmingly, some staff nurses have described uncertainty as to the purpose of admissions which have lasted up to 4 years [18].

The term malignant regression [19] describes the circumstance in which a patient deteriorates and becomes more suicidal in hospital, a potential consequence to containing risk. Given that some patients diagnosed with BPD can have difficulties in maintaining stable interpersonal relationships, a busy ward with up to twenty-eight patients alongside overlapping shift patterns of nurses and doctors, can be a medley of misunderstanding. These misunderstandings (in particular the possible perception of abandonment at the end of crisis intervention) can be potential triggers to self-destructive behaviour; the use of hospitalization needs to be carefully considered, as it rests on an ethical tightrope. 
Constant observations in particular are a costly resource which not only infringes on the privacy of the patient, but as described, formally transfers the responsibility for personal safety from patient to clinician. An interesting aside comes in discussing which clinician adopts this. Although observations are an intervention led and delivered by nurses, they still tend to have much of their authority and decision making within the hands of medical staff. Whilst a complex issue which cannot be done full justice here, it is worth considering whether or not this 'pass the parcel' transfer of responsibility, from patient to doctor via nurse, has an impact on the motives behind, and the delivery of care. Although it could be strongly argued that decisions and responsibility should be shared, the virtues, duties and consequences behind a decision may be blurred if interventions are prescribed for a patient, delegated by a doctor, but facilitated by a nurse.

Constant observation clearly highlights the shift in responsibility as a nurse literally watches a patient sleep, go to the bathroom and eat their meals. The consequential maleficence of these interventions 
has a tandem association with the longevity of them. If used on a short term basis the consequential beneficence can still be justified as, in the immediacy of crisis, they can save lives [15]. However long-term interventions, whether admissions or use of constant observations, are clear violations of non-maleficence. If interventions become long-term, it could be argued that patients are being encouraged to depend on the healthcare system for their own safety, as they lose coping mechanisms and the ability to control any selfdestructive impulses. It could also be argued that these measures respond only pragmatically to the behaviour, and not empathetically to the underlying distress.

With a view to avoiding these damaging consequences, tolerating risk can be an example of clinicians motivated by beneficence. If a patient can maintain their autonomy, the consequences of risk tolerance are beneficent. Paris [12] states the paradox that to treat any chronic suicidal ideation in the patient with BPD effectively, the patient must have the option to die. Whilst this may initially be a 
challenging idea, it can open the door to a patient developing their own coping mechanisms, and a truly patient led recovery.

\section{The Maleficence of Tolerating Risk}

However, tolerating risk is obviously not without the potential for negative outcomes. The potential violation of non-maleficence comes in this tolerance cultivating a complacency which puts patients, in need of intervention, at risk. In tolerating risk, teams must have an agreed threshold for how much they can reasonably allow. A damaging potential could be a habitual complacency. Whilst tolerating risk may have beneficent motives, if it becomes ritualistic habit and not a serious and unique test of judgement, then the maleficent consequences present through clinician complacency, and an increased risk to patients.

Given the fragile nature of people diagnosed with BPD, particularly around interpreting the motives of others, tolerating risk can also fuel a patients feelings of low self-worth and self-loathing and see an increase in acts, or threat of self-harming and suicidal behaviour. If a 
patient perceives that their pain is not being taken seriously, they may feel the need to provide a physical demonstration, and thus 'prove' their distress. This impulsiveness in the face of perceived rejection has to be viewed alongside the reason for assessment, without a clinician adopting responsibility. Therapeutic relationships and an effort to thoroughly explore thoughts and feelings, as precursors to behaviour, should be essential practice. This issue highlights the importance of explicit empathy, and clear communication of the intent behind clinical decisions.

Fundamentally, clinicians must continue to assess each patient, and each presentation, as completely unique. Anyone working with patients with BPD would benefit from an ability to tolerate risk, without this tolerance becoming neglect. Whilst any assessment will prove challenging, an essential distinction in deciding between measures of containment and tolerance comes in differentiating between the acute and long term risks of suicide.

\section{Defining risk: Acute vs Long term Risk}


A first step prior to using the action/consequences model of BPD risk management is to define the classification of risk. Suicidal thoughts can be experienced by some people diagnosed with BPD, with these thoughts often a chronic and enduring feature of the disorder. A distinction therefore must be made between the acute risk of suicide, and the long term risk which is one of the key features in the DSM's [1] diagnostic criteria. Bateman and Krawitz [15] describe a baseline suicidality with episodic acute suicidality. The baseline represents the enduring long term risk, and calls for a different approach to any acute episode.

Without an ability to tolerate long term risk, the health service would see every presenting patient with BPD admitted to an inpatient unit, placed on constant observations and detained under the mental health act... forever. Now besides being obvious that 'forever' is not financially sustainable, the greater concern would be the detriment to the patient previously discussed. NICE [3] support the importance of this distinction, stating "while risks to self and others must not be dismissed, it is also important to distinguish between long-term risks 
and acute ones. Failure to do so can lead to an exaggerated and inappropriate response to long-term risks". It does however have to be acknowledged that making this distinction may not be easy for any health professional, and particularly those faced with a patient they have met for the first time. Therefore this distinction is best made within the context of knowing your patient, or having detailed notes and crisis plans readily available to assessing clinicians.

Our 'actions' within the model, the acts of tolerating and containing risk, can be most appropriately applied to these two alternate scenarios, and uniquely relate to the principles of beneficence and non-maleficence dependant on whether the risk of suicide is acute or long term. Whilst long-term risk needs to be tolerated to allow a patient to maintain personal responsibility, acute risks need to be thoroughly assessed and can merit containment. If acute risk is to be tolerated, this would be appropriate only within the context of a thorough assessment, team consensus regarding diagnosis and an established pattern of behaviour [20]. Ultimately, tolerance of long term risk allows the patient to maintain autonomy and a sense of 
control over their own behaviours, while containment could cause lasting harm and foster dependency.

Containing risk is appropriate in some situations of acute suicidality, particularly where toleration could lead to a neglect of imminent suicide risk. Whilst hospitalization has no evidence base for its value in treating suicidality in BPD, there can be no doubt of its potential to save lives. It is making the distinction between these two classifications of risk, and responding appropriately, which presents the on-going challenge for clinicians. Creating a foundation for the use of the action/consequence model, any action of tolerance or containment must first define the risk as chronic or acute. This challenge is made all the more difficult by the rules, regulations and reputation of the nursing and medical professions, in the context of increasingly scrutinising societal eyes.

\section{Public Perception and Professional Reputation}

Given that assessment of risk rests with the subjective view of the clinician, it is easy to understand why the paternalistic hindsight of 
outside parties can create an atmosphere of apprehension. The clinicians concerns may not only involve the patient's immediate safety and long-term outcomes, but the views of the said patient, public, media, regulatory and legal bodies. Both the tolerance and containment of risk have been discussed with a view to the patients benefit, although there can be other motivations in play. The pressure on clinicians can prompt decision making which goes beyond patient-centred morality, moving from doing the right thing, and into the territory of being seen to do the right thing.

Defensive psychiatry is defined by Simon [21] as "any act or omission that is performed not for the benefit of the patient but to avoid malpractice liability or to provide a legal defence against a malpractice claim". Here any debate on beneficence and nonmaleficence takes a backseat to the motivation of clinicians, with crisis intervention sometimes indicating clinician helplessness [22]. Fagin illustrates that "the fears of what might happen if these patients are not contained inevitably lead to admission" [23]. These fears are likely a double edged sword of worry, capturing a genuine 
anxiety around the patient's safety along with a fear of resulting litigation were the patient to come to any harm. If clinicians as moral agents decide the best course of action for a patients benefit, we can justify these actions (on a short or long term basis) through duty, intention or consequences. However, should actions become focused on the clinician and the avoidance of malpractice claims, the duty to the patient will have become secondary to self-interest, leaving any intervention void of ethical merit. Alarmingly, one study found up to $85 \%$ of clinicians had at one time, based decisions on this sense of professional self-preservation [24].

This self-interest may also be fuelled by organisational and professional pressure which can further impact on decision-making. The NMC code states that nurses should "act with integrity and uphold the reputation of your profession at all times" [25]. The reputation of nursing as a whole can be affected by a public who perhaps do not understand the ethical difficulties explored in terms of assessing and managing risk. To the layman, an obvious conclusion to draw from containing risk is that the staff involved are full of care 
and compassion, and deeply concerned by a patient's safety. The flip side to this coin is in a potential public perception of tolerating risk as neglect. For people who do not understand the nature of BPD, and the value of the sometime appropriate 'less is more' approach, tolerating risk can seem misguided, uncaring and even immoral. If we look at the moral debate of acts and omissions and adopt the view that letting someone die is in effect the same as killing them, clinicians failing to 'act' and contain the threat of suicide could be labelled with a damning moral judgement which could only wash off with mass public education and understanding.

Regulatory bodies, despite their intentions or principles, may be swayed by public opinion and feel the teleological need to be seen to 'do something' in cases where somebody may have come to harm. Knowing this 'something' can affect professional registration; it is easy to see why doctors and nurses could make a link between the risk of patient suicide and the subsequent risk to their professional career. Despite the maleficence which can come from intervention, containment is the option which is simpler to understand in terms of 
its 'visible caring' and 'quick and easy' moral justification. Therefore the nursing and medical professions need to be careful that they adequately support, and do not persecute, staff who may face these difficult decisions on a daily basis. A 'customer is always right' approach to investigations by regulatory bodies will only serve to intimidate mental health staff into acting against their professional instincts [26]. The NHS Quality Strategy [9] emphasises that care should be safe, person centred and effective. It could be argued that defensiveness sees an over-emphasis on 'safe', which could see staff rely too heavily on containment, to the detriment of 'person centred' care and 'effective' treatment. 
The Action/ Consequence model of BPD Risk Management

\begin{tabular}{|c|c|c|c|c|c|}
\hline Consequence & $\begin{array}{l}\text { Potential } \\
\text { Benefit }\end{array}$ & $\begin{array}{l}\text { Potential } \\
\text { Danger }\end{array}$ & $\begin{array}{l}\text { Potential } \\
\text { Short- } \\
\text { term } \\
\text { impact }\end{array}$ & $\begin{array}{l}\text { Potential } \\
\text { Long-term } \\
\text { impact }\end{array}$ & $\begin{array}{l}\text { Potential } \\
\text { I nterpretation } \\
\text { of Clinician } \\
\text { Motive }\end{array}$ \\
\hline Tolerating Risk & $\begin{array}{l}\text { Patient } \\
\text { Autonomy }\end{array}$ & $\begin{array}{l}\text { Clinician } \\
\text { Complacency } \\
\text { / Patient } \\
\text { Suicide }\end{array}$ & $\begin{array}{l}\text { Short Term } \\
\text { Risk }\end{array}$ & $\begin{array}{l}\text { Long Term } \\
\text { Autonomy }\end{array}$ & $\begin{array}{l}\text { Neglect of } \\
\text { Patient }\end{array}$ \\
\hline $\begin{array}{l}\text { Containing } \\
\text { Risk }\end{array}$ & $\begin{array}{l}\text { Patient } \\
\text { Safety }\end{array}$ & $\begin{array}{l}\text { Patient } \\
\text { Dependence }\end{array}$ & $\begin{array}{l}\text { Short Term } \\
\text { Safety }\end{array}$ & $\begin{array}{l}\text { Long Term } \\
\text { Dependency }\end{array}$ & $\begin{array}{l}\text { Care and } \\
\text { Compassion }\end{array}$ \\
\hline
\end{tabular}

The following worked example, based on clinical experience, demonstrates the use of the model, with reference to a hypothetical patient. The model is to be a guide and a capturing of issues to increase awareness, and promote a 'bearing in mind' to aid clinician decision making: 
Kiki is a 27 year old female with a diagnosis of BPD, currently experiencing suicidal ideation. She is met by a clinician who faces the challenging task of assessing whether the suicidal thoughts pose an acute and imminent risk, or whether they are consistent long-term with her baseline chronic condition. Based on this assessment, made within the context of knowing the patient or having detailed notes and crisis plans available, the clinician should be deciding on whether or not to contain, or tolerate risk. During this process, the decision making is aided by reflecting on the potential benefits, and dangers of either course of action. A potential benefit to Kiki having her risk contained is that she will be safe. Whilst it can be agreed that she may not be 'well', this could be an intervention that could save her life. The danger with containment is that Kiki could potentially become dependent, with crisis intervention emphasising her helplessness, and her feeling that she needs to rely on mental health services for her personal safety.

Nevertheless, there is the possibility that the risk, if deemed chronic and enduring, could be tolerated. The benefit to this is that Kiki 
maintains her autonomy. Avoiding dependence can be achieved clinically by placing an emphasis on crisis planning, identifying Kiki's patterns of behaviour, triggers, and early warning signs. Moreover minimizing the effectiveness of mental health services in times of crisis is an important strategy [15]. This will encourage the development of Kiki's individual coping mechanisms, rather than reinforce her belief that she needs professional intervention to keep herself safe. Kiki may however, interpret any toleration of risk as neglect, and a discrediting of her distress. She may choose to provide further demonstrations of her distress through self-harm, suicidal behaviour, or communicating her intentions to do so. Ultimately, the clinician should not take responsibility for Kiki's behaviour, and the same principles should apply to the assessment process. The true flip side to this tolerating coin comes in the potential of dangerous clinician complacency, which can be to miss the signs of acute as opposed to chronic distress. For these reasons, every patient must be seen as unique, every presentation be seen as unique, and the model used to aid decision making rather than promoting one fixed approach which becomes habitual. 
Once an intervention, or non-intervention, has been decided on, it is then useful to continue through the model looking at timescale. This will not only be useful on initial assessment, but also to add clarity to the success of intervention if it becomes prolonged and benefit is in doubt. Whilst Kiki could have her risk of suicide contained, it needs to be acknowledged by clinicians that this is likely to be a short term benefit only, and that the long-term implications is a delayed risk of dependency. Therefore if admission/intervention moves from 24-72 hours into a week or more, the model provides a framework from which potential iatrogenic harm can be highlighted. It would be hoped that the model would emphasise maleficence, and justify a change of approach, long before Kiki's length of admission moved from weeks to months to years.

However, if Kiki's clinician feels it is appropriate to tolerate suicidal ideation, assessing the risk as chronic rather than acute, the model could provide reassurance that whilst there is a risk taken, this risk is ultimately short-term. Tolerating risk avoids the delayed risk of 
containment, promoting a beneficent patient empowerment and autonomy, rather than a maleficent dependency on services. With Kiki having control over her own impulses, she would have an opportunity to re-establish coping mechanisms, or develop new ones.

Finally, the model highlights how a clinician's decision may be seen. This should relate to how the decision is viewed by Kiki, but also colleagues, organisations and the wider public. This latter stage is hoped to encourage clinicians to step back and consider how their decision and motives may be interpreted, with an awareness that potential interpretations may influence their decision making. Taking this into account, the clinician should ask themselves if their actions are truly virtuous, and intended to benefit Kiki. It is through this selfreflection that one would hope to avoid a defensive psychiatry, where containment is selected as it 'looks good', and emphasises a duty to care and compassion whilst smiling in the face of on-looking regulatory bodies and public. Whilst it may be appropriate to contain Kiki's risk, it is important this is done to her benefit, considering the benefits versus the dangers on both a short-term and long-term 
basis. Any care which is provided as it 'looks good' for the clinician, rather than from a genuine belief that it will benefit Kiki, is void of virtue.

Furthermore, containment is easy compared to tolerating risk, and it is hoped that this model could reassure clinicians and provide a framework for helping justify more difficult decision making. Whilst Kiki voices suicidal ideation, it may be felt that intervention would be detrimental for some of the reasons discussed. Although the reasoning behind a decision should always be clearly communicated, there is the potential, particularly in patients with BPD known for misunderstanding motives, that this will be misinterpreted. A clinician may decide to tolerate Kiki's risk, only to have Kiki feel as if she is being neglected and that the clinician doesn't care. She may have family that also feel this way, and often to the layman, with no awareness of the person, pattern of behaviour or diagnostic understanding, it does initially appear this way. There may also be anxiety regarding how a decision will be viewed by regulatory bodies, but the model could provide a framework for justification of action. 
In this way, the model not only provides a framework to help reassure decision makers of their motives and intentions, but also encourages them to clearly communicate and document throughout the decision making process.

There are many potential outcomes for Kiki, and it is appreciated that this model cannot fully capture the dynamics of specific individuals, environments and circumstances, however, it can be a useful aid to decision making and crisis management.

\section{Discussion}

The care of an inpatient with BPD involves walking a tightrope between establishing conditions to make the patient safe, and avoiding the complete removal of their personal responsibility [23]. This difficulty can be highlighted with reference to the NMC code, which states that nurses must "act without delay if...there is a risk to patient safety", whilst also attempting to "reduce as far as possible any potential for harm associated with your practice" [25]. A distinction is needed between the long-term and acute risks of suicide 
as a precursor to the use of the action/consequences model, where a delicate balance needs to be struck between containment and tolerance of these risks.

Acute risk is more likely to merit containment, and can be morally justified in terms of a duty to maintain imminent safety. If acting on long-term risk, containment is a detrimental reinforcement of patient helplessness and over time will likely increase the acute risk. Longterm risk warrants an approach guided by tolerance, with beneficent consequences being a maintained autonomy and personal coping mechanisms. However, should this tolerance foster a complacency of acute risks, the beneficence clearly transforms into a violation of nonmaleficence.

Whilst the accountability of health professionals is necessary to promote excellence in care, their motivations should not be relentlessly questioned. As professions made up of selfless soldiers who should all have an innate caring instinct, mental health professionals working with people diagnosed with BPD will have 
beneficent motives which can sometimes backfire into maleficent consequences. Regardless of the views of moral merit being in duty, motive or consequence, ethical scrutiny first requires a knowledge of the person, and understanding of the fragility and patterns of behaviour of people with BPD, before discussions around beneficence and non-maleficence can yield results. A simplified stand-off between act and omission is not helpful as sometimes in this patient group, paradoxically, the best intervention can be a well thought out, professionally justified and well-communicated non-intervention. The communication and empathy in the clinician/patient interaction is paramount, with fruitful responses not a direct mirroring of the patients anxiety, but a contingent marked mirroring [27] which acknowledges the distress, without resorting to an anxious or panicked response, and carefully selects the intervention, or nonintervention, to the patients benefit.

Whilst this may be a conclusion which appears to lack a definitive finality, the essence and purpose of this paper is to highlight the ethical challenges which may initially lack transparency. It is the 
responsibility of all health professionals to treat each person on an individual basis, whilst having an understanding of the diagnoses of people they treat, and from this point hold an awareness of the ethical duties, intentions and consequences of their actions.

The action/consequences model captures the issues of beneficence and non-maleficence within the context of risk assessment, potential benefits, potential dangers, potential timescales and potential interpretation of motives. It would be hoped that whilst it is notexhaustive of all potential challenges, that it can prove a useful tool in clinical decision making and risk assessment. In using this model as a process, an essential element would be communicating the decision making process clearly to the patient, showing honesty around the thought processes, motives and justifications for any action. Working with people diagnosed with BPD can be challenging, and the diversity of individuals makes any black and white approach an impossibility. In assessment of risk and ethical deliberation, the conclusion will be grey, unique to every patient, every presentation and every clinician. 


\section{References}

1. American Psychiatric Association. Diagnostic and Statistical Manual of Mental Disorders, Fifth Edition. Arlington, VA: American Psychiatric Association, 2013.

2. World Health Organisation. The ICD-10 classification of mental and behavioural disorders: clinical descriptions and diagnostic guidelines. Geneva: World Health Organization, 1992.

3. NICE. GC78: Borderline Personality Disorder - Treatment and Management.

http://www.ncbi.nlm.nih.gov/books/NBK55403/pdf/Bookshelf_ NBK55403.pdf (2009, accessed 21 ${ }^{\text {st }}$ December 2015).

4. Dasgupta P. and Barber J. Admission patterns of patients with personality disorder. Psychiatr Bull 2004; 28(9), pp. 321-323.

5. Paris J. Chronic suicidality among patients with borderline personality disorder'. Psychiatr Serv 2002; 53(6), pp. 738-742.

6. Borshmann R., Henderson C., Hogg J., Phillips R. and Moran P. Crisis interventions for people with borderline personality disorder (Review), The Cochrane Library, 2012; (6), pp. 1-24. 
7. Zanarini MC., Frankenburg FR, Khera GS. et al. Treatment histories of borderline inpatients. Compr Psychiatry 2001; 42(2), pp. 144-150.

8. The Scottish Government. Constant Observation: Elements of Good Practice.

http://www.scotland.gov.uk/Publications/2002/08/15296/1045 $\underline{2}$ (2005, accessed 21 December 2015).

9. The Scottish Government. The NHS Quality Strategy. http://www.gov.scot/resource/0039/00398762.pdf (2012, accessed 21 December 2015).

10. Mental Health (Care and Treatment) (Scotland) Act 2003

11. Kant I. The Moral Law: Groundwork of the metaphysics of morals, Translated and analysed by H.J Paton. London: Routledge, 1948.

12. Paris J. Treatment of borderline personality disorder: A guide to evidence-based practice. New York: The Guilford Press, 2008.

13. Paris J. Commentary on the American Psychiatric Association guidelines for the treatment of borderline 
personality disorder: evidence-based psychiatry and the quality of evidence. 2002; J Personal Disord, 16(2), pp. 130-134.

14. Oldham JM. Borderline personality disorder and suicidality. Am J Psychiatry 2006; 163(1), pp. 20-26.

15. Bateman AW and Krawitz R. Borderline personality disorder: An evidence-based guide for generalist mental health professionals. Oxford: Oxford University Press, 2013.

16. Paris J. Is hospitalization useful for suicidal patients with borderline personality disorder? J Personal Disord 2004; 18(3), pp. 240-247.

17. Gallop R. Self-destructive and impulsive behaviour in the patient with a borderline personality disorder: rethinking hospital treatment and management. Arch Psychiatr Nurs 1992; 6(3), pp. 178-182.

18. Warrender D. Staff nurse perceptions of the impact of mentalization based therapy skills training when working with borderline personality disorder in acute mental health: a qualitative study, J Psychiatr Ment Health Nurs 2015; 22(8), pp. 623-633. 
19. Dawson D and McMillan HL. Relationship Management of the Borderline Patient: From Understanding to Treatment. Brunner/Mazel: New York, 1993.

20. Krawitz R, Jackson W, Allen R. et al. Professionally indicated short-term risk-taking in the treatment of borderline personality disorder. Australas Psychiatry 2004; 12(1), pp.1117.

21. Simon RI. Defensive psychiatry and the disruption of treatment boundaries', Isr J Psychiatr Rel 2000; 37(2), pp. 124-131.

22. Friedman FB. Borderline personality disorder and hospitalization. Soc Work Ment Health 2008; 6(1-2), pp. 67-84.

23. Fagin L. Management of personality disorders in acute inpatient settings. Part 1: Borderline personality disorders. Adv Psychiatr Treat 2004; 10(2), pp. 93-99.

24. Krawitz R and Batcheler M. Borderline personality disorder: a pilot study about clinician views on defensive practice. Australas Psychiatry 2006; 14, pp.320-322. 
25. NMC. The Code: Standards of conduct, performance and ethics for nurses and midwives. http://www.nmcuk.org/Publications/Standards/The-code//ntroduction/ (2015, accessed 21 December 2015)

26. Warrender D. From the heart: tolerating risk in borderline personality disorder. Royal College of Nursing, RCN Bulletin. 2014; 321, November 2, p. 7.

27. Bateman A and Fonagy P. Mentalization-based treatment for borderline personality disorder: A practical guide. Oxford: Oxford University Press, 2006, p.11. 